\title{
SERIA POSSÍVEL TRANSPLANTE HEPÁTICO EM MULHER BRASILEIRA DA AMAZÔNIA COM INSUFICIÊNCIA HEPÁTICA AGUDA?
}

\author{
Would it be possible to perform liver transplantation in a Brazilian Amazon woman with \\ acute liver failure?
}

Aline Pinto Alves, Daniel Felgueiras Rolo, Danielle Cristina Silva Moura, Gracieli Pâmela Spolti e Lucas Crociati Meguins

\begin{abstract}
RESUMO
A insuficiência hepática aguda (IHA) é caracterizada por deterioração hepática súbita e presença de encefalopatia ou coagulopatia, consequente a infecções e drogas, entre outros. Uma paciente com exames sorológicos para leptospirose e hepatite A positivos (anti-leptospira IgM e anti-HAV IgM foram positivos) apresentou IHA e faleceu após seis dias de tratamento clínico. Em conclusão, a IHA devido à coinfecção pode evoluir ao óbito e, talvez, o transplante hepático de emergência, além de ser a única opção de tratamento possível, pode ser também a última chance de sobrevivência.
\end{abstract}

Descritores: Insuficiência Hepática, Leptospirose, Hepatite A, Transplante hepático.

Instituições:

Faculdade de Medicina da Universidade Federal do Pará. Belém, Pará, Brasil.

\section{Correspondência:}

Gracieli Pâmela Spolti

Rua São Miguel, 1806 CEP: 66065-690. Belém, Pará, Brasil.

Fone:(91) 3250-7043, (91) 8172-8912

e-mail: gracielipamela@gmail.com

Recebido em: 13.11 .2009

\section{INTRODUÇÃO}

A insuficiência hepática aguda (IHA) é uma síndrome clínica incomum e dramática, caracterizada pela rápida deterioração da função hepática, resultando em encefalopatia hepática e/ou coagulopatia em pacientes com fígado previamente normal. A hepatite viral e lesão hepática induzida por drogas são responsáveis pela maioria dos casos de IHA. ${ }^{1-3}$ Além disso, formas complicadas de certas doenças infecciosas podem se assemelhar à IHA consequente à hepatite viral aguda, e deve ser considerada no diagnóstico diferencial de pacientes com hepatite fulminante. ${ }^{4}$

Este estudo objetiva descrever o caso de uma mulher adulta com co-infecção por leptospirose e hepatite A que evoluiu com IHA, e discutir a possibilidade e importância do transplante hepático para esse tipo de paciente.

\section{RELATO DE CASO}

Uma mulher de 33 anos, nascida e residente na região amazônica brasileira foi admitida no departamento de doenças infecciosas do hospital público local, com histórico de três dias de icterícia, febre e tontura, com desenvolvimento subsequente de urina escura. De acordo com a paciente, dois meses antes da admissão já havia apresentado quadro semelhante com febre, icterícia e dor abdominal, tendo recebido diagnóstico de hepatite A. Durante 
exame físico, observou-se febre $\left(38,5^{\circ} \mathrm{C}\right)$, icterícia $(4+/ 4+)$ e desidratação $(2+/ 4+)$.

Após 12 horas da admissão para investigação clínica, a paciente apresentava hepatomegalia, confusão mental e agitação psicomotora, evoluindo em seguida para o estado de coma, compatível com nível IV de encefalopatia. A paciente foi transferida para a unidade de tratamento intensivo (UTI) e mantida com suporte clínico. A investigação bioquímica revelou níveis séricos de creatinina de $1,4 \mathrm{mg} / \mathrm{dL}(123,7 \mu \mathrm{mol} / \mathrm{L})$, uréia 54 $\mathrm{mg} / \mathrm{dL}(9,0 \mu \mathrm{mol} / \mathrm{L})$, glicose $54 \mathrm{mg} / \mathrm{dL}(29,97 \mu \mathrm{mol} / \mathrm{L})$, bilirrubina total 23,9 mg/dL $(408,69 \mu \mathrm{mol} / \mathrm{L})$, AST $263 \mathrm{U} / \mathrm{L}$, ALT $667 \mathrm{U} / \mathrm{L}$, fosfatase alcalina $120 \mathrm{U} / \mathrm{L}, \gamma$-glutamiltransferase (GGT) $54 \mathrm{U} / \mathrm{L}$, proteínas totais $5,7 \mathrm{~g} / \mathrm{dL}$, albumina $2,2 \mathrm{~g} / \mathrm{dL}, \mathrm{pH}$ 7,03 e tempo de protrombina de 120 segundos.

A investigação sorológica foi realizada, tendo evidenciado presença de anticorpos anti-HAV IgM e IgG e anticorpos anti-leptospira IgM, ambos pelo método ELISA. Apesar da administração do suporte clínico preconizado para IHA, a paciente apresentou complicações com síndrome hepatorrenal, choque refratário, insuficiência de múltiplos órgãos e óbito no $6^{\circ}$ dia de UTI.

\section{DISCUSSÃO}

A insuficiência hepática aguda (IHA) é uma síndrome clínica incomum e dramática, caracterizada pela presença de encefalopatia hepática, coagulopatia e anormalidades metabólicas devido à intensa necrose aguda do fígado. ${ }^{2} \mathrm{~A}$ hepatite viral e lesão hepática induzidas por drogas são responsáveis pela maioria dos casos de IHA, ${ }^{1-3}$ mas o diagnóstico diferencial com doenças infecciosas que podem causar sintomas semelhantes à IHA é importante, principalmente em países sub-desenvolvidos e em desenvolvimento. ${ }^{4-6}$ Além disso, a associação entre doenças infecciosas e hepatite viral, embora rara, pode resultar em IHA.?

A elevada incidência de infecções de maneira isolada por leptospirose e hepatite A é comum em várias regiões do Brasil e em países tropicais, e tais doenças geralmente estão associadas às precárias condições de saneamento básico e evolução individual favorável, porém, cada uma pode evoluir para IHA. ${ }^{4,8} \mathrm{O}$ risco de IHA é menor na hepatite A, porém, aumenta conforme a idade e tempo de exposição ${ }^{2}$ e a co-infecção pode ser um fator de prognóstico ruim.

No presente caso, a suspeita clínica de co-infecção leptospirose e hepatite A foi confirmada sorologicamente (anti-leptospira IgM e anti-HAV IgM foram positivos), e a existência dessas duas condições num mesmo indivíduo ao mesmo tempo tem sido relatada como causa clínica para IHA, ${ }^{4,7}$ situação que apresenta elevada taxa de mortalidade. ${ }^{7,9}$ A paciente evoluiu a óbito apesar do suporte clínico para IHA, questionando-se assim se o transplante hepático total teria sido uma opção terapêutica possível nesse caso.

O fígado recupera-se inteiramente, tanto na estrutura quanto na sua função, quando o paciente sobrevive à crise de insuficiência hepática aguda. No entanto, até esse estágio ser alcançado, é essencial a realização de medidas terapêuticas para diminuir o alto risco de mortalidade por IHA, como o suporte clínico adequado ou outras alternativas como MARS, ${ }^{6,10}$, destacando-se a realização do transplante ortotópico. ${ }^{9,11,12}$

Em pacientes bem selecionados, o transplante hepático é o único tratamento que tem demonstrado aumento de sobrevida. ${ }^{11,12}$ Os critérios de Clichy $^{13}$ e do King's College ${ }^{14}$ são os dois mais importantes sistemas de pontuação utilizados para transplante hepático em pacientes selecionados com IHA. ${ }^{12}$ Mundialmente, o transplante hepático aparece como principal opção terapêutica em pacientes que preenchem critérios de Clichy ou do King's College. ${ }^{11}$ Neste relato de caso, a paciente preenchia os critérios do King's College para IHA não induzida por paracetamol, como o tempo de protrombina, que foi de 120 segundos (tempo de protrombina $>100$ s). Entretanto, o critério de Clichy não pôde ser aplicado porque a medida do fator $\mathrm{V}$ não estava disponível. ${ }^{12}$

Segundo a legislação brasileira, a paciente tinha indicação para transplante hepático,${ }^{15}$ no entanto, o procedimento não foi realizado, indicado, ou mesmo discutido pela equipe médica, tendo em vista que não há serviço que realiza transplante hepático em Belém ou na região Norte do Brasil. ${ }^{16}$ A evolução desfavorável da paciente ocorreu durante os seis dias de internação hospitalar, o que, caso houvesse serviço de transplante de fígado na região da Amazônia brasileira, seria tempo suficiente para que a mesma fosse submetida ao procedimento e sobrevivesse às complicações da IHA.

Há dificuldades relacionadas ao transplante, como risco de óbito durante o procedimento ou no pós-operatório imediato, sobretudo em paciente instável como aqueles com IHA, além das limitações após transplante, como adesão à terapia imunossupressora e as maiores dificuldades, que são a urgência do processo e a inexistência de um serviço de transplante local. ${ }^{9}$ Tais dificuldades devem ser ponderadas, mas não se deve ignorar que com a realização do transplante hepático, o paciente com IHA recebe boa chance de sobreviver. ${ }^{9,11,12}$

Em conclusão, este caso destaca que a co-infecção hepatite A e leptospirose pode evoluir para IHA e, talvez, o transplante hepático não seria a única opção terapêutica possível, mas a última chance de sobrevivência para pacientes que apresentem esta emergência médica.

\section{ABSTRACT}

Acute liver failure (ALF) is characterized by acute liver damage and the presence of encephalopathy or coagulopathy due to infections, drugs, etc. A female patient with positive serological tests for leptospirosis and Hepatitis A virus (anti-leptospira IgM and anti-HAV IgM positive) developed ALF and died within six days after clinic treatment. In conclusion, ALF due to co-infection may evolve to death and maybe the emergency liver transplantation added to be the only feasible treatment option may be also the last chance to survival.

Keywords: Liver failure, Leptospirosis, Hepatitis A, Liver Transplantation. 


\section{REFERÊNCIAS}

1. Lee WM. Acute liver failure. N Engl J Med 1993;329(25):1862-72.

2. O'Grady JG. Acute liver failure. Postgrad Med J. 2005;81:148-54.

3. Areia M, Romãozinho JM, Ferreira M, Amaro P, Leitão C. Fulminant hepatic failure: a portuguese experience. Eur J Gastroenterol Hepatol. 2007;19:665-9.

4. Deepak NA, Patel ND. Differential diagnosis of acute liver failure in India. Ann Hepatol. 2006;5(3):150-6.

5. Bounlu K, Insisiengmay S, Vanthanouvong K, Saykham , Widjaja S, Iinuma K, et al. Acute jaundice in Vientiane, Lao People's Democratic Republic. Clin Infect Dis. 1998;27(4):717-21.

6. Penafiel A, Devanand A, Tan HK, Eng P. Use of molecular adsorbent recirculating system in acute liver failure attributable to dengue hemorrhagic fever. J Intensive Care Med. 2006;21(6):369-71.

7. Ghoshal UC, Somani S, Chetri K, Akhtar P, Aggarwal R, Naik SR. Plasmodium falciparum and hepatitis E virus co-infection in fulminant hepatic failure (abstract). Indian J Gastroenterol. 2001;20(3):111.

8. Ciocca M, Moreira-Silva SF, Alegría S, Galoppo MC, Ruttiman R, Porta G, et al Hepatitis A as an etiologic agent of acute liver failure in Latin America. Pediatr Infect Dis J. 2007;26(8):711-5.
9. Sette Jr H, et al. Insuficiência hepática aguda grave. Lopes AC. Tratado de Clínica Médica. 2ed, 2009.

10. Covic A, Maftei ID, Gusbeth-Tatomir P. Acute liver failure due to leptospirosis successfully treated with MARS (molecular adsorbent recirculating system) dialysis. Int Urol Nephrol. 2007;39(1):313-6.

11. De Rave S, Tilanus HW, Van Der Linden J, De Man RA, Van Der Berg B, Hop WC, et al. The importance of orthotopic liver transplantation in acute hepatic failure. Transpl Int. 2002;15(1):29-33.

12. Renner EL. How to decide when to list a patient with acute liver failure for liver transplantation? Clichy or King's College criteria, or something else? J Hepatol. 2007;46(4):554-7.

13. Bismuth H, Samuel D, Castaing D, Adam R, Saliba F, Johann M, et al. Orthotopic liver transplantation in fulminant and subfulminant hepatitis. The Paul Brousse experience. Ann Surg. 1995;222:109-19.

14. O'Grady JG, Alexander GJ, Hayllar KM, Williams R. Early indicators of prognosis in fulminant hepatic failure. Gastroenterology. 1989;97(2):439-45.

15. Brasil. Ministério da Saúde. Portaria $n^{\circ} 1.160$ de 29 de maio de 2006. Diário Oficial República Federativa do Brasil. 2006.

16. Brasil. Sistema Nacional de Transplante. Transplante de Órgãos e UF 2001 a 2006. 